\title{
Desafios da organização e da regulação da educação superior em Timor-Leste e a questão da capacitação institucional
}

\section{Resumo}

Este trabalho aborda aspectos da educação superior, no âmbito do Ministério da Educação e das instituições, em Timor-Leste. As questões e objetivos desta abordagem dizem respeito à organização e à regulação da educação superior e à capacitação institucional. Para abordar tais questões, foi feita uma análise dos principais documentos oficiais relativos ao tema, associada à atuação deste autor em grupos de trabalho e em programas de capacitação e assessoramento no Ministério, em 2004 e 2005. As ações desenvolvidas e a presente análise levaram em consideração aspectos da realidade histórico-cultural do país e

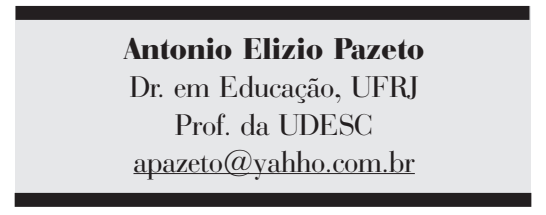
procedimentos conjuntos com as "contrapartes" timorenses. Em decorrência dessa concepção, foram alcançados os seguintes resultados: elaboração dos termos de referência para a organização do Ministério; definição de agenda para estruturação da educação superior; elaboração de proposta da legislação educacional para o Ministério da Educação; finalização do Plano de Política Nacional de Educação 20052010; elaboração de proposta de Estatuto para a Universidade Nacional Timor Lorosa'e - UNTL. Não obstante as limitações em rela- ção aos quadros humanos, recursos técnicos e financeiros e das peculiaridades históricoculturais e políticas daquele país, encontramse delineadas as bases de referência para a organização, regulação e capacitação institucional no âmbito do Ministério da Educação e, em particular, da educação superior.

Palavras-chave: Educação superior. Organização e regulação. Capacitação institucional e consultoria. Identidade cultural e colonização. 
and the institutional capacity building. To approach such issues, an analysis of the official documents concerning this matter was done, associating the performance of this author in working groups and in the programmes for capacitating and advising at the Ministry in 2004 and 2005. The development of these programmes and of the analysis of the documents have taken into consideration the historical and cultural realities of that country and the procedures alongside the Timorese counterparts. In view of this, the following proposals were reached: Terms of reference and an agenda for organizing the Ministry of Education and the Higher Education system; Educational laws for the Ministry of Education; Plan of National Policies of Education from 2005 to 2010; Chapter of the National University of Timor Lorosa'e - UNTL. Despite the difficulties in relation to the human, technical and financial resources and of the historical, cultural and political issues from the TimorLeste colonization, the basis of reference for the organizing, regulating and the institutional capacity building were made in the scope of the Ministry of Education and, especially, for the Higher Education system.

Keywords: Higher Education.

Organization and regulation. Institutional capacity building and consultancy.

Cultural identity and colonization.

\section{Resumen}

Desafíos de la

organización y de la regulación de la educación superior en Timor Este y la cuestión de la capacitación
Este trabajo aborda aspectos de la educación superior, en el ámbito del Ministerio de la Educación y de las instituciones, en Timor Este. Las cuestiones y objetivos de este abordaje dicen respecto a la organización y a la regulación superior y a la capacitación institucional. Para abordar estas cuestiones, fue hecha un análisis de los principales documentos oficiales relativos al tema, asociada a la actuación de este autor, en grupos de trabajo y en programas de capacitación y asesoramiento en el Ministerio, en 2004 y 2005. Las acciones desarrolladas y el presente análisis llevaron en consideración aspectos de la realidad historia y cultural del país y procedimientos conjuntos con las "contrapartes" de Timor Este. Como consecuencia de esta concepción, fueron alcanzados los siguientes resultados: elaboración de los tiempos de referencia para la organización del Ministerio; definición de la agenda para la estructuración de la educación superior; elaboración de propuesta de la legislación educacional para el Ministerio de la Educación ; finalización del Plan de la Política de la Educación 2005 - 2010; elaboración de propuesta de Estatuto para la Universidad Nacional Timor Lorosa e UNTL. No obstante las limitaciones con relación a los cuadros humanos, recursos técnicos y financieros $y$ de las peculiaridades históricas, culturales y políticas de aquel país, fueron delineadas las bases de referencia para la organización, regulación y capacitación institucional en el ámbito del Ministerio de la Educación y, en particular, de la educación superior.

Palabras clave: Educación superior. Organización y regulación. Capacitación institucional y consultoría. Identidad cultural y colonización. 


\section{Introdução}

Como outras regiões colonizadas pelo Estado Português, Timor-Leste apresenta uma história de dominação e de lutas, visando à sua Independência, ainda pouco conhecida. Por ocasião da participação do autor deste trabalho, na condição de membro da Missão Brasileira MEC/ CAPES, em 2004, e da Missão de Suporte à Força de Paz da ONU, em 2005 em ambos os casos como Consultor em Administração da Educação -, foi sentido de perto o problema da educação naquele país, particularmente, no que diz respeito à educação superior.

Os programas desenvolvidos ao longo da Missão procuraram criar as condições para a organização do sistema educativo, em sentido mais amplo, com ênfase na formação de gestores e na organização da educação superior.

Frente ao quadro de conflitos pelo qual passara o povo timorense e, considerando mais de quatro séculos de colonização portuguesa, esse fato vem-se constituindo o principal cenário de desafios, tanto para a Missão Brasileira, quanto para outros governos ou organizações internacionais comprometidos em dar suporte a Timor-Leste.
Uma das primeiras atitudes adotadas, quando do início dos trabalhos, foi analisar a situação em que se encontrava a Diretoria Nacional de Educação Superior no contexto do Ministério, e o funcionamento das instituições de educação superior em relação à organização e regulação'. Outra atitude consistiu em definir com os pares do Ministério da Educação um Termo de Referência ${ }^{2}$ que traçasse as bases para a consecução das metas previstas no Acordo entre os dois Governos ${ }^{3}$. A partir desse quadro, a capacitação institucional ${ }^{4}$, constituiu-se em diretriz norteadora e justificadora dos compromissos e das ações a serem implementadas ao longo dos dois anos.

Por se tratar de trabalho desenvolvido em uma realidade distinta da que se conhece no mundo ocidental, a ambientação cultural e a confiança necessárias para estabelecer uma interlocução produtiva tornaram-se estratégia e condição para empreender quaisquer programas, inclusive de convivência com os pares timorenses. Frente a esse contexto, o despojamento em relação a valores preconcebidos, concepções teóricas ou hábitos adquiridos no processo de formação próprio da realidade brasileira mereceram especial atenção diante de uma realidade diversa e desconhecida a que este autor acabara de integrar.

\footnotetext{
1 Para efeitos da presente análise entende-se por organização a existência de condições e de instrumentos administrativos no âmbito do Ministério da Educação e das instituições universitárias que dêem suporte e ordenamento à educação superior. Por regulação entende-se a existência de atos autorizativos que dêem às instituições e aos cursos legalidade e legitimidade em benefício dos que deles se utilizam.

2 Termo de Referência é uma expressão corrente mo âmbito das Agências de Cooperação Internacional, que estabelece as orientações e condições em que determinados planos de ação devem ser desenvolvidos e resultados alcançados.

${ }^{3}$ Memorando de Entendimento assinado pelo Representante das Nações Unidas Sérgio Vieira de Mello e o Embaixador Kywal de Oliveira, em 24/08/2001, e Acordo de Cooperação Educacional firmado em 20/05/2002 entre o Ministro Celso Lafer - Relações Exteriores (Brasil), e o Ministro José Ramos Horta-Negócios Estrangeiros e Cooperação(Timor-Leste).

${ }^{4}$ A expressão "Capacitação institucional" tem base conceitual referida às expressões Institutional capacity building ou Capacity of development aplicadas, com mais propriedade, pelas Agências das Nações Unidas. Seu conteúdo diz respeito à aquisição de sinergia por meio de atividades conjugadas e orientadas para programas bilaterais entre governos, por meio de capacitação de órgãos governamentais e criação de redes de parcerias de capacitação e desenvolvimento das instituições.
} 
Era pressuposto a este autor que atuação em realidades socioculturais heterogêneas, requeria atitudes de prudência e de abertura à questão da diversidade cultural, como condição para o diálogo e eficácia dos trabalhos. Esse quadro de percepções e de referências, não obstante muitas incertezas, balizou atitudes e ações empreendidas, tendo em vista os objetivos e metas propostos.

O suporte ao desenvolvimento da educação superior em Timor-Leste foi orientado por uma atitude investigativa e de caráter interativo, com base nos compromissos definidos nos Acordos de Cooperação e respectivas agências responsáveis pelo desenvolvimento dos programas.

Com base nas informações iniciais sobre a situação da educação no país e, de modo particular, sobre a educação superior, duas questões básicas nortearam os trabalhos: Qual a situação da organização e da regulação da educação superior no âmbito do Ministério da Educação, e quais as condições para o exercício da gestão por parte dos gestores institucionais, no âmbito do Ministério da Educação e no âmbito das instituições de educação superior.

Frente a tais questões e desafios, os seguintes objetivos foram traçados: Definir parâmetros para a organização e regulação da educação superior, e elaborar estratégias de suporte à capacitação institucional dos gestores educacionais.

Delimitados o problema e os objetivos anteriormente apresentados, a investigação a ser levada a efeito utilizou-se dos seguintes instrumentos: observação participante e pesquisa-ação; análise documental; contatos com professores e gestores educacionais.
Complementaram as estratégias de pesquisa: encontros interativos com os atores parceiros; levantamento de informações sobre a organização do Ministério e a situação das instituições de educação superior; definição de princípios e de conceitos básicos para a construção de propostas conjuntas.

Três documentos governamentais, que expressam a política educacional e seus ordenamentos, foram objeto de análise: Plano Nacional de Desenvolvimento; Política Nacional de Educação e a proposta de Lei de Bases do Sistema Educativo, além de relatórios e outros documentos de suporte utilizados pelo Ministério da Educação.

\section{Contextualização e independência de Timor-Leste}

Não é demais dizer, inicialmente, que Timor-Leste é um país situado entre, aproximadamente, 17.000 ilhas do Sudeste da Ásia, tendo ao sul o Mar de Timor, frente à Austrália, e ao norte o Mar de Banda, frente ao Arquipélago da Indonésia e ao Mar do Sul da China.

Timor-Leste tem uma extensão territorial de 18.900 quilômetros quadrados e, aproximadamente, 925.000 habitantes. Está organizado em 13 Distritos que, por sua vez, compreendem 67 Sub-distritos e 498 Sucos e Aldeias. Essa organização resulta da estrutura secular de suas comunidades, combinada com a organização geopolítica do $191^{\circ}$ Estado-membro das Nações Unidas, criado em 2001. Em termos de extensão e de população, sem muita dificuldade, TimorLeste pode ser comparado a duas dezenas de Municípios brasileiros de porte médio, ou ainda, ao Estado de Sergipe. 
Ainda que, sumariamente, é necessário situar Timor-Leste no contexto das regiões colonizadas, como uma das últimas colônias lusófonas, situada no mundo oriental, que lutou por sua emancipação e, após um dos mais longos processos de colonização, teve sua independência restaurada diante do domínio indonésio, com o primeiro Governo instalado em 2002.

Originalmente, esse país esteve sob domínio português desde 1514. Em 1975, beneficiando-se das mudanças decorrentes da Revolução dos Cravos e da queda do regime militar salazarista de Portugal, Timor-Leste declarou sua Independência.

Por temer que o movimento pela emancipação tivesse orientação marxista, no mesmo ano, os Estados Unidos deram apoio ao Governo da Indonésia para que TimorLeste fosse invadido e anexado como sua $27^{a}$ Província (CUNHA, 2001).

As línguas oficiais em Timor-Leste, como definido na Constituição, são o Português e o Tétum. São consideradas línguas de trabalho o Indonésio e o Inglês. No entanto, até o presente momento, nenhuma dessas línguas é falada por toda a população. Em decorrência das culturas locais, sobretudo na zona rural onde reside em torno de $70 \%$ da população, são conhecidas outras 26 línguas, dialetos ou subdialetos, segundo levantamento do Instituto de Lingüística na Universidade Nacional Timor Lorosa'e (UNITED NATIONS, 2003).

Estudioso lingüista australiano, Hull (HULL; CORTE-REAL, 2002, p. 38-39) assim se expressa ao se referir às línguas em Timor-Leste:

realidade, convém agrupar as línguas usadas em Timor-Leste em duas cate- gorias. Devem-se distinguir as línguas que desde há muito fazem parte da cultura local, das línguas que há pouco tempo foram introduzidas. Na primeira categoria, a das línguas que se podem classificar como verdadeiramente nacionais, estão o tétum, os outros catorze vernáculos e a variedade timorense do português (que tem características próprias e por vezes arcaizantes). Na outra categoria, a das línguas estrangeiras, cujo impacto nos vernáculos indígenas não foi tão profundo como foi o do português, o inglês e o indonésio.

A instalação da República Democrática de Timor-Leste, deu-se em 20 de maio de 2002, sob o regime da nova Constituição e a posse do primeiro Governo eleito democraticamente - Presidente Kay Rala Xanana Gusmão. $\bigcirc$ período compreendido entre 1999 até a instalação do novo Governo, foi acompanhado pelo ConseIho de Segurança das Nações Unidas por meio da United Nations Transitional Administration in East Timor - UNTAET, com mandato de Missão de Administração de Transição entre o domínio indonésio e o Estado independente. Após a instalação do novo Governo, foi a UNTAET transformada em United Nations Mission of Support in East Timor - UNMISET, Missão de Suporte a Timor-Leste, ambas sob mandato do Conselho de Segurança da ONU, cuja finalidade primordial foi constituir-se como Força de Manutenção da Paz e de suporte ao desenvolvimento institucional.

Com a retirada da Força de Paz da ONU, integrada por exércitos de 7 países, dentre eles o Brasil, em 20 de maio de 2005, - Conselho de Segurança das Nações Unidas decidiu manter apoio a algumas áreas 
estratégicas e mais carentes de quadros humanos especializados, por meio de um Escritório das Nações Unidas no país, denominado United Nations Office in East Timor - UNOTIL.

impacto desse conjunto de medidas vem assegurando, presentemente, as condições para a construção da sustentabilidade e da capacitação e desenvolvimento institucional do país, como propugnam os Objetivos de Desenvolvimento do Milênio das Nações Unidas. Segundo esse preceito, o princípio da sustentabilidade adquire expressão e efetividade por meio da capacitação e desenvolvimento institucional.

Com base nos preceitos das Nações Unidas, capacitação e desenvolvimento institucional constituem, nas palavras de Browne (2002, p. 1-2), "um processo de longo prazo que cobre etapas cruciais, incluindo capacitação, segurança, domínio nacional e sustentabilidade [...]", abrangendo níveis individual, institucional e da sociedade como um todo. Sob esse prisma, sustentabilidade e capacitação e desenvolvimento institucional tornam-se termo de referência das nações signatárias da Carta das Nações Unidas para desenvolvimento de programas de Cooperação Internacional comprometidos com a construção da autonomia e da liberdade das nações integrantes.

Sem que se faça, no entanto, uma análise histórico-cultural sobre o impacto dos períodos de domínio português e indonésio, sobre a parte oriental da llha de Timor - hoje Timor-Leste -, não se terá condições de compreender os processos de formação desse novo Estado e os desafios relacionados às ações de governo, particularmente, em função da cultura regional, das limita- ções relativas à qualificação de quadros humanos e da insuficiência de recursos no âmbito do governo.

Um estudo levado a efeito nos anos 80 por Neave (1992) em relação à Cooperação Internacional do tipo Norte-Sul, embora afeto ao âmbito das universidades européias, tem demonstrado que esse tipo de cooperação traz consigo o conceito de "Estado Avaliador" que acompanha o processo de cooperação, determinando uma espécie de controle "a distância", em vista de modelos definidos pelo Estado.

Mutatis mutandis, para o objeto ora em análise, no que concerne à cooperação de Governos ou Agências de Cooperação por parte de países centrais frente a países periféricos, trata-se, segundo Canto e Hannah (2006, p. 219), de um

modelo tradicional de colaboração referido por Neave (1992), como 'forma clássica de cooperação', por algumas pessoas como 'cooperação técnica' e por outros especialistas, 'parceria vertical' ou mesmo 'parceria assimétrica'.

Em qualquer dos casos, essa forma de cooperação se dá no contexto histórico do colonialismo, em que a colaboração entre países desenvolvidos e em desenvolvimento segue a equação centro/periferia, embora apresente uma forma avançada ou neocolonial, como indicam as autoras. E concluem:

Em contraste com a modalidade tradicional de cooperação, a cooperação avançada ou neocolonial deve ser entendida como uma parceria avançada desde que preste não somente apoio tradicional, mas também permita o desenvolvimento de projetos de pesquisa conjuntos. Ao contrário de programas assistenciais, essa nova moda- 
lidade de parceria está baseada também no intercâmbio de conhecimento e, nesse contexto, parece que a mudança de atitude de ambos os lados é uma questão muito importante a ser considerada (CANTO; HANNAH, p. 228-229).

Boa parte dos programas de cooperação que vem sendo levados a efeito em Timor-Leste, como se presenciou, não demonstra forma avançada ou neocolonial, como anteriormente referido, embora esse seja o discurso, pela ausência de intercâmbio e de parceria a ponto de haver mudança de atitudes de ambos os lados. Os programas continuam mantendo relações verticais, de natureza centro/periferia, com indicadores claramente assimétricos.

As limitações e dificuldades que vêm sendo constatadas decorrem, sobretudo, dos 445 anos de exploração a que esse país foi submetido, sem receber qualquer tipo de investimento, acrescidos dos 24 anos de domínio militar indonésio, cujo regime impôs mudanças estruturais profundas naquela região ocupada. Se, de uma parte, o longo período de colonização portuguesa em nada contribuiu para o desenvolvimento dessa região, a Língua Portuguesa e a Religião Católica foram formadoras de uma determinada cultura, cujas marcas se mesclaram às culturas nativas, de influência chinesa e malaia, que remontam ao século XIII, atraídas pela exploração de sândalo e de mel, hoje completamente extintos.

Na condição de colônia ultramarina, Timor-Leste mantivera-se isolada e distante de qualquer possibilidade de desenvolvi- mento, quer pela condição de ilha, quer pelas limitadas perspectivas de retorno econômico e político por parte do Estado Português. Para se ter uma idéia do grau de alienação, a primeira escola pública criada pelo Governo de Portugal aconteceu apenas em 1962, praticamente, 450 anos após ocupação daquela longínqua ilha.

Diferentemente do processo de colonização portuguesa, o curto período de domínio indonésio - 1975 a 1999 -, promoveu investimentos em infra-estrutura e em educação com a finalidade de conquistar a adesão timorense no sentido de desestruturar as identidades e valores locais oriundos da cultura ocidental construídos ao longo do período anterior, e de criar estruturas de cooptação e de submissão. Nesse período, o Governo Indonésio implantou as primeiras escolas públicas no país.

Com o intuito de assegurar o domínio territorial, o regime indonésio tratou de substituir os referenciais até então em vigor - particularmente, a Língua Portuguesa -, pela Língua Indonésia bem como apoiou as Religiões Católica e Muçulmana. Em vista disso, enviou professores indonésios à região, como estratégia de subordinar os timorenses ao Estado Indonésio, imprimindo uma educação de subserviência ao novo regime.

Desde 2003, em conseqüência dos conflitos havidos em 19995, o Governo de Timor-Leste vem, com apoio da comunidade internacional, reconstruindo a rede escolar. Igual esforço vem sendo des-

\footnotetext{
${ }^{5}$ Além da destruição da infraestrutura escolar, outro problema diz respeito ao desaparecimento da maioria dos registros e documentos escolares ou pessoais, acarretando impossibilidade de comprovação por parte dos estudantes em relação à continuidade dos estudos. Esse problema não só dificulta identificar o nível em que o estudante se encontra como também o surgimento de instituições atraindo estudantes em "cursos superiores" ofertados livremente.
} 
tinado à organização e implantação do currículo escolar, à elaboração de sebentas $^{6}$, programas de formação de professores e cursos de Língua Portuguesa intensificados. Tais esforços por parte do Governo timorense e da comunidade internacional decorrem dos programas desenvolvidos pelas Agências das Nações Unidas. Por ser signatário das Metas de Desenvolvimento do Milênio, Timor-Leste aderiu ao programa "Educação para Todos - Via Rápida de Escolarização"7, que prevê a universalização da educação primária de 6 anos a toda a população de 7 a doze 12 anos.

Com o intuito de colaborar na aceleração desse processo, o Acordo de Cooperação entre os Governos do Brasil e de Timor-Leste vem viabilizando, desde 2003, o envio de consultores e de professores para intensificar a formação de professores timorenses e o suporte à organização e capacitação institucional no âmbito do Ministério da Educação, entre outros órgãos.

À medida que a estrutura física é gradualmente reconstruída e professores começam a ser preparados, o Ministério da Educação vem organizando o sistema educativo, com prioridade para a educação primária (6 anos) e, a partir de 2005, a educação pré-secundária (3 anos). A educação secundária (3 anos) e a educação superior ainda não são prioritárias. Num primeiro momento e com esse intuito, o Governo vem apoiando escolas particulares a atuarem nesse segmento.

\section{Situação da educação superior}

A educação superior em Timor-Leste foi implantada em 1986, época em que a região ainda estava sob domínio indonésio. No período compreendido entre 1986 e 1999, três instituições de educação superior criadas pela Indonésia promoviam cursos em TimorLeste: Universitas Timor Timur - UNTIM, Politeknik Dili e Pendidikan Guru Sekolah Dasar de Dili ${ }^{8}$, cujo contingente de estudantes alcançou a cifra de, aproximadamente, 4.000. Essas instituições, seguindo o modelo de educação superior indonésio, ofereciam cursos de três anos (bacharelato) e de quatro anos (licenciatura), podendo ser obtidos diplomas parciais ao final de cada ano, dependendo do tipo de curso e do número de anos que o aluno desejasse freqüentar.

Com o advento do Referendo Popular, em 30 de agosto de 1999, seguido do anúncio do resultado final a favor da Restauração da Independência, intensificaramse os enfrentamentos das milícias civis e militares decorrentes da reação dos "próintegracionistas" à Indonésia contra os "pró-libertação" timorense. Com o agravamento da crise, o país foi devastado, com reflexos ainda hoje evidentes, particularmente em Dili, afetando profundamente a infraestrutura física e a estrutura familiar e de trabalho do povo timorense.

Além da destruição das escolas, os professores indonésios que lecionavam em Timor-Leste retornaram a seu país de origem,

\footnotetext{
${ }^{6}$ Denominação usada para textos produzidos sob a forma de apostilas, por professores portugueses e brasileiros, que servem para subsidiar os professores timorenses em suas aulas, especialmente na escola primária. As sebentas tomam o lugar dos livros didáticos ainda inexistentes nas escolas, podendo vir a ser impressos sob a forma de livros, nos próximos anos.

${ }^{7} \mathrm{O}$ programa denominado Education For All: Fast Track Iniciative é patrocinado por países parceiros do G-8 e agências de suporte, administrado pelo Banco Mundial.

${ }^{8}$ Denominação, em Língua Indonésia, das três instituições de educação superior implantadas em Dili.
} 
deixando a população sem professores. Diante desse quadro de crise, as primeiras escolas e instituições de educação primária a educação superior já em funcionamento, ficaram desprovidas de toda e qualquer condição física e docente, retomando, parcialmente, suas atividades, a partir de 2001 (CUNHA, 2001).

Em 2000, a United Nations Transitional Administration in East Timor - UNTAET criou um programa de bolsas de estudo denominado Timor Lorosa'e Scholarship Programme - TLSP, que possibilitou a 1.500 estudantes universitários do último semestre, continuarem os estudos na Indonésia, mediante apoio financeiro destinado para esse fim por organismos internacionais. Ainda em novembro de 2000, a UNTAET instalou a Universidade Nacional Timor Lorosa'e - UNTL, oriunda da fusão da Universitas Timor Timur e da Politeknik Dili. Nessa época, foi decisiva a participação do Diplomata Sérgio Vieira de Melo na condição de Representante Especial do Secretário Geral das Nações Unidas, tanto na criação da Universidade Nacional e na reorganização e funcionamento de escolas, quanto na preparação das condições para a instalação do novo Estado e do primeiro Governo.

Em 2003, relatórios preliminares elaborados pela Japan International Cooperation Agency (2003) apontavam a existência de 17 instituições de educação superior atuando no território timorense. Além da Universidade Nacional Timor Lorosa'e - UNTL, única instituição oficial credenciada, com 7.900 alunos matriculados, outras 16 instituições privadas atuavam em Dili, capital do país, ou Baucau, segunda maior cidade. Dentre elas, 7 instituições auto-intitula- vam-se Universidades - algumas delas com menos de 300 alunos -, 3 Academias e 6 Institutos, algumas dessas instituições, inclusive, com campus em mais de uma cidade. $\bigcirc$ conjunto das 16 instituições privadas apresentava matrícula de 5.550 estudantes, que somados à UNTL, totalizava 13.450 estudantes.

Recente levantamento indica os seguintes cursos em funcionamento: Saúde Pública, Economia, Contabilidade, Administração, Ciências Sociais, Ciência Política, Relações Internacionais, Ciências do Mar e da Pesca, Manejo Florestal e Animal, Medicina, Direito, Engenharia: Civil, Elétrica, Mecânica, Industrial e Agrícola, Arquitetura, Agronomia, Teologia e Ciências Religiosas, Matemática, Física, Química, Biologia, Formação de Professores para a Escola Primária, Ciências da Educação, Computação, Economia Doméstica, Turismo e Hospitalidade, Línguas: Português, Tétum e Inglês.

Algumas das instituições e cursos recebem suporte técnico, financeiro e docente do Japão, Austrália, Portugal e, mais recentemente, de Cuba. Independentemente de apoios externos, os estudantes pagam entre 10 e 30 dólares por semestre, para estudarem na Universidade Nacional, e um valor variável entre 120 e 280 dólares por semestre, dependendo das condições financeiras e dos cursos, para estudarem nas instituições privadas.

Países da região da Ásia e Europa vêm intensificando a oferta de bolsas de estudo, em nível de graduação e de pós-graduação, como é o caso do Brasil, para estudantes ampliarem oportunidades de especialização e obterem nível de educação mais avançado. 
Em relação às condições de funcionamento, os prédios e as instalações físicas apresentam-se muito precárias. Acervo bibliográfico, laboratórios ou recursos técnicos, em muitos casos, são inexistentes. A grande maioria dos professores tem apenas nível de graduação, sendo muito poucos os que possuem titulação em nível de mestrado ou doutorado.

De outra parte, o Ministério da Educação não possui cadastro ou censo que assegure as informações básicas sobre a situação da educação superior no país, dificultando, sobremaneira, conhecer e administrar esse segmento da educação, com mais propriedade.

Sem qualquer base estrutural e sem padrões de referência, a educação superior em Timor-Leste, com algumas exceções, apresenta uma situação precária, não atendendo aos padrões internacionais, a não ser em relação à Indonésia, mesmo assim, não de todo.

Não obstante a educação superior estar em funcionamento há duas décadas, sua organização e desenvolvimento não dispõem da regulamentação necessária, cuja elaboração vem sendo levada a efeito desde 2004.

funcionamento de alguns cursos superiores, como foi constatado por professores brasileiros 9 , segue uma prática que vem desde a época do domínio indonésio. Os estudantes ingressam na universidade mediante prova descritiva. $\bigcirc$ curso é estruturado em créditos, valendo cada crédito três horas-aula (50 a 60 minutos por aula), e a freqüência exigida é de 75\%. É atribuída uma hora de estudos de caráter pessoal, para cada crédito desenvolvido em sala de aula. Um crédito equivale, portanto, a quatro horas. $O$ semestre letivo, por sua vez, tem em média 20 créditos por disciplina, perfazendo um total de 80 horas. A média de créditos dos cursos é de 156, perfazendo um total de 624 horas-aula.

De outra parte, os estudantes não têm o hábito de assiduidade integral às aulas, não atendendo à pontualidade em relação ao início e término das aulas bem como aos 75\% de freqüência exigida por disciplina. Qualquer penalidade aplicada pelo nãoatendimento à freqüência mínima, não é aceita pelos estudantes, acarretando dificuldades para os professores. Além disso, os estudantes não têm o hábito de fazer tarefas domésticas solicitadas pelos professores. Tais exigências somente são cumpridas se os professores destinarem um período de aula para essa finalidade. Qualquer horário extraclasse proposto pelos professores tem pouca receptividade por parte dos estudantes.

\section{Documentos norteadores da educação superior}

Inspirado nos preceitos da Constituição da República Democrática de Timor-Leste, o primeiro documento oficial que trata das políticas nacionais de desenvolvimento, elaborado com vistas a orientar o Governo, é o Plano Nacional de Desenvolvimento, aprovado em 2003. Por ser um documento de políticas de governo, no que diz respeito à educação superior o Plano prevê um Programa de Desenvolvimento da Educação Universitária com três projetos: Fortalecimento

\footnotetext{
9 Um dos relatos é da professora Fabiana Ribas, bióloga brasileira que integra a Missão brasileira desde 2005. Sua atuação como docente voluntária na UNTL, ao longo de um ano, permitiu apontar algumas características do meio universitário em Timor-Leste.
} 
Institucional; Preenchimento dos Quadros; Elaboração de Currículo. É com base nesse documento que o Ministério da Educação vem direcionando suas políticas e programas.

O segundo documento, concluído em 2005, denomina-se Política Nacional da Educação. Em relação à educação superior, o documento aponta os seguintes projetos: Criação do Conselho Nacional de Educação; Criação do Comitê de Educação Superior; Definição de Parâmetros Nacionais para Acreditação de Instituições e de Cursos Superiores; Organização e Avaliação de Instituições e de Cursos; Programas de Intercâmbios.

O terceiro documento de referência para a educação superior é a Lei de Bases do Sistema Educativo - a primeira lei que regula a educação em Timor-Leste. Este projeto de lei, produzido e debatido por mais de dois anos com ampla participação de lideranças dos Distritos, dirigentes educacionais e professores - e com presença de consultores brasileiros -, foi concluído em 2005 e encaminhado às instâncias de aprovação.

No capítulo reservado à educação superior, a Lei de Bases prevê princípios, finalidade e objetivos da educação superior; critérios para organizar e regular as Instituições de Educação Superior; autonomia universitária, graus e diplomas acadêmicos; sistema de acreditação, avaliação, acesso e promoção dos estudantes; política para formação de professores e de pesquisadores universitários; diretrizes para o financiamento da educação superior. Define, ainda, que a Universidade Nacional Timor Lorosa'e - UNTL exercerá papel de convalidação e registro dos estudos até então praticados livremente no país, medi- ante delegação de competência do Ministério da Educação e com base em procedimentos específicos de avaliação. A Lei de Bases do Sistema Educativo define, ainda, que a educação superior poderá ser desenvolvida por instituições de caráter particular e cooperativo, atendendo, para tanto, regulamentação específica já elaborada e encaminhada à aprovação oficial.

Desde o início das atividades deste autor no Ministério da Educação, chamava atenção a importância dada ao Plano Nacional de Desenvolvimento e ao documento de Política Nacional de Educação, em detrimento, à primeira vista, da Lei de Bases do Sistema Educativo, que não recebia a mesma atenção e prioridade. Parecia soar estranho, pois, convencionalmente, sem uma única lei de educação para o país, não seria possível ordenar e fazer funcionar com regularidade o sistema de educação.

Ao longo da atuação na Diretoria Nacional de Educação Superior e do assessoramento ao Ministro da Educação, ficou evidenciado que o Governo priorizava definição de políticas e de programas nacionais de educação como condição para obter apoio das agências e organismos patrocinadores internacionais, que se comprometiam em financiar programas de educação a fundo perdido, na maioria dos casos sob a coordenação do Banco Mundial. Além dessa constatação, um componente de ordem cultural aliava-se à constatação do retardamento da provação da Lei de Bases do Sistema Educativo. Depoimentos de funcionários de diferentes órgãos do Governo confirmavam que a longa história de colonização inviabilizara práticas de governo com base em leis, pois as autoridades ad hoc, em outros tempos, interpretavam os ordenamen- 
tos de acordo com as circunstâncias e as conveniências de cada situação - hábito enraizado e de difícil superação.

No presente momento, o panorama da educação superior apresenta graves desafios: regulação das atividades de educação superior que vêm sendo desenvolvidas sem parâmetros e normas oficiais, nem padrões de referência; institucionalização de um padrão de educação superior para atender às exigências nacionais e internacionais; formação de quadros especializados para atuar na educação superior e na sua gestão, extensiva à administração pública em geral.

A participação nas etapas finais da elaboração, tanto do documento de Política Nacional de Educação quanto da Lei de Bases do Sistema Educativo, por parte deste autor, em cujas atividades foi dedicada a maior parte do tempo, tem constatado distorções e contradições acentuadas, tanto na produção dos documentos, quanto nos trâmites internos. Dependendo dos consultores que atuavam na elaboração dos documentos, estes passavam a ser "propriedade" ora de uns, ora de outros. Proposições eram acolhidas segundo os consultores ou os patrocinadores de plantão, sem que houvesse posicionamento decisivo por parte dos dirigentes locais. Não era incomum a circulação de documentos paralelos, elaborados com a finalidade de conturbar os grupos de trabalho e facilitar a aprovação de documentos diferentes, oriundos de grupos aliados a interesses corporativos.

Constatou-se também - e o problema continua persistindo -, descontinuidade em relação a trabalhos contratados por meio de consultorias. Após meses de trabalho, terminados alguns contratos, consultores eram substituídos por outros que retomavam os trabalhos, sem qualquer noção dos processos já desenvolvidos. Ou ainda, trabalhos eram interrompidos em conseqüência de percalços de ordem burocrática por parte de agências patrocinadoras, determinando abandono de programas aprovados ou em andamento.

Tais situações demonstravam evidente dificuldade de coordenação frente às consultorias patrocinadas por agências internacionais que prestavam suporte ao $\mathrm{Mi}$ nistério, acarretando prejuízos de toda ordem à organização e ao desenvolvimento da educação no país.

\section{Diretoria Nacional de Educação Superior}

O Ministério da Educação de TimorLeste tem em sua estrutura organizacional a Diretoria Nacional de Educação Superior como órgão responsável por todas as questões afins a essa área. A partir de 2004, a Diretoria, com apoio de agências e especialistas internacionais, vem promovendo debates, cursos e seminários com instituições de educação superior e professores com o propósito de definir parâmetros para a organização dos currículos, padrões de funcionamento dos cursos e regulação da educação superior. Paralelamente, o Ministério vem tratando da aprovação da Política Nacional de Educação e da Lei de Bases do Sistema Educativo - condições primordiais para a ordenação e o desenvolvimento da educação superior.

Na medida em que a Diretoria Nacional de Educação Superior vem propondo padrões e critérios para esse âmbito, tornamse mais evidentes os problemas e desafios 
que envolvem a educação superior e as conseqüências que essa situação poderá trazer para as próximas décadas ${ }^{10}$, se tais critérios não forem implementados a curto prazo.

Não obstante os esforços no sentido de regulação da educação superior, as limitações, sobretudo, de ordem normativa, administrativa e de pessoal qualificado, dificultam a produção e implementação de instrumentos para sua estruturação. Os organismos internacionais que vêm se comprometendo com o suporte à educação em Timor-Leste centram-se na educação primária e pré-secundária, ficando a educação secundária e superior sem o apoio necessário.

A experiência tem demonstrado que as influências externas sobre Timor-Leste, sejam elas de ordem cultural ou política, tanto oriundas dos países do ocidente quanto do mundo asiático, exercem absoluta preponderância sobre a ainda frágil estrutura política, financeira e administrativa local. A falta de experiência e a dificuldade no que diz respeito à tomada de decisão em relação à organização e gestão da educação superior, por parte dos que atuam nessa área, e a dependência do Ministério da Educação aos organismos patrocinadores, representam os maiores desafios na definição e implementação de estratégias de capacitação institucional.

A raiz e as conseqüências desse quadro são os quase cinco séculos de colonização sem qualquer investimento nos quadros humano e social. Não obstante a Independência restaurada pelo Referendo Popular, muitos dos programas de suporte ao desenvolvimento da educação correm o risco de perpetuarem o processo de colonização ao invés de reverterem essa situação. Evidências desse quadro vêm sendo constatadas por meio da organização dos currículos em todos os graus e níveis escolares, do uso da Língua Portuguesa e línguas estrangeiras e do material didático definidos com base em outros países ou modelos educacionais, sem coordenação e tomada de decisão timorense. A constatação da dificuldade por parte dos dirigentes do Ministério em atuar de forma decisiva no sentido de "filtrar" as propostas oriundas dos consultores internacionais é uma das fragilidades na gestão dos programas educacionais, de difícil superação.

esforço do Ministério com o apoio de organizações externas, no intuito de promover capacitação institucional, não conseguia neutralizar a ingerência de determinados interesses que atuavam em sentido contrário. Prova desse enfrentamento era a atuação de consultores ou assessores que defendiam, diante dos dirigentes do Ministério da Educação, a não-adoção de determinados conceitos, normas, modelos curriculares ou terminologia educacional que não fossem validados pela literatura ou instituições de seus países de origem, dificultando ainda mais o esforço por uma capacitação institucional sustentável. Ou ainda, a exigência de que se reproduzisse a legislação educacional de seus países de origem como padrão para o sistema educativo de Timor-Leste.

Não bastassem essas atitudes que visavam a inviabilizar processos de construção de autonomia, testemunhou-se a defesa de propostas de não oferta de determinados con-

\footnotetext{
${ }^{10}$ Com o intuito de minimizar os problemas, foi apresentado ao Ministério da Educação proposta deste autor, sustando qualquer nova iniciativa em relação à abertura de cursos, vagas e instituições de educação superior. Despacho Ministerial, nesse sentido, foi assinado pelo Senhor Ministro da Educação Prof. Armindo Maia, em 18/08/2004.
} 
teúdos curriculares em cursos de formação de professores, pois tais conteúdos não teriam condições de serem assimilados pelos estudantes timorenses. A alegada justificativa era, segundo alguns propositores, a incapacidade decorrente do baixo nível cultural, que os professores e estudantes apresentavam em desenvolver exercícios que exigiam raciocínio sistemático, de ordem filosófica ou lógico-matemática.

Tais situações contrariam a perspectiva de capacitação institucional e demonstram o grau de dificuldade por que vêm passando os responsáveis pela implantação do sistema educativo em Timor-Leste.

Por tratar-se de argumentos apresentados por consultores oriundos de países europeus, essa situação parece explicar a pretensa supremacia da ciência do Norte para resolver os problemas do Sul, denunciada por Santos (2004).

A experiência vivida nesse período de atuação demonstrou que a definição de marcos conceituais discutidos, registrados e disseminados entre os pares veio a constituir-se estratégia eficaz para os dirigentes estabelecerem parâmetros próprios que fundamentem a organização e capacitação institucional no âmbito da educação em todos os graus e níveis. Sem o estabelecimento de um conjunto de referenciais apropriados à realidade do país, como também o protagonismo dos dirigentes frente à coordenação de tais processos, nada do que existe ou está sendo produzido poderá vir a assegurar a sustentabilidade e autonomia desejadas.

\section{Considerações finais}

É importante não só reconhecer os primeiros caminhos traçados mas, sobretudo, os esforços inegáveis que vêm sendo envida- dos pelo Ministério da Educação, professores e consultores, de um modo geral, tanto em relação aos níveis iniciais do sistema educativo quanto à educação superior. No entanto, para os dirigentes educacionais e consultores comprometidos com a implantação de um sistema educativo adequado à realidade daquele país, esse começo exige esforço e atenção redobrados, pois a sensação de impotência frente às limitações de toda ordem existentes ultrapassa as condições e perspectivas dadas até o momento presente.

A situação em torno da qual a educação superior vem sendo desenvolvida, sem que se apresente um padrão de referência construído em parceria com os dirigentes educacionais timorenses, tende a se agravar, comprometendo, ainda mais, as possibilidades de superação.

Além dos três documentos referenciais já apresentados: Plano Nacional de Desenvolvimento, que traça as prioridades nacionais; Plano Nacional de Educação, que orienta as prioridades e os programas do Ministério; Lei de Bases do Sistema Educativo, que traça entre outros, a organização e o perfil da educação superior, esforços e investimentos intensos necessitam ser feitos por um longo período, para desenvolver competências requeridas em relação à regulação e desenvolvimento da educação, de forma auto-sustentável.

Promover capacitação institucional em circunstâncias como as que foram apresentadas, requer diligente exercício de mudança de atitude em relação à tomada de decisão assumida por parte dos dirigentes educacionais, de tal forma que estes se coloquem na condição de protagonistas e de coordenadores das ações, ao invés de se limita- 
rem à adoção de propostas definidas por consultores e agências internacionais ou mesmo por organismos patrocinadores.

Mais especificamente em relação à educação superior, para que esses princípios e intentos alcancem nova performance, é necessário que seja intensificado, a curto prazo, um conjunto de medidas, tais como: organização administrativa e definição de instrumentos de regulação da educação superior; preparação de quadros humanos em todos os níveis; definição de padrões e normas para os currículos e funcionamento dos cursos; elaboração dos regulamentos institucionais para as universidades e outros tipos de instituições; incremento de recursos financeiros para dar suporte à infra-estrurura e a programas de formação de professores e de gestores educacionais. Os esforços e medidas que vêm sendo implementados e as ações em curso são, ainda que importantes, incipientes e não permitem vislumbrar, no curto prazo, possibilidade de reverter a situação em vigor.

Por se tratar de um país integrante da Comunidade de Países de Língua Portuguesa CPLP, é papel da comunidade internacional e, não menos, da comunidade lusófona, ampliar o suporte para setores estratégicos de Timor-Leste, dentre eles a educação superior, cuja participação, até o presente momento, é tímida e muito aquém das necessidades. A vontade políitica dos dirigentes daquele país, se não acompanhada de efetiva cooperação da comunidade internacional, pode tornar-se componente de frustração e de medidas sem qualquer perspectiva sustentável.

Quaisquer esforços que visem, atualmente, a contribuir com o Estado e com a sociedade timorense, no que diz respeito ao desenvolvimento da capacitação institucional, requerem, da parte dos Governos e das Agências de Cooperação, ações fundadas no conhecimento e na valorização da realidade sociocultural daquele país e implementadas com as lideranças timorenses e não para os timorenses. A compreensão dos fenômenos socioculturais que formaram aquela sociedade e a criação de estratégias que abriguem e fortaleçam sua identidade e suas instituições constituem a base para todo e qualquer empreendimento comprometido com a construção da autonomia daquela sociedade e de seu desenvolvimento sustentável.

A implementação das políticas educacionais e, particularmente, das condições necessárias à organização, regulação e gestão da educação superior em Timor-Leste estão diretamente associadas às questões da redescoberta e cultivo da identidade cultural timorense.

A desagregação da cultura regional decorrente da imposição de culturas externas, provocou, como conseqüência, perda das próprias referências e fragilização da identidade pessoal e institucional, ao longo da história. A essa perda de referências, é necessário acrescentar as limitações relativas à formação dos quadros humanos, cujo grau de dificuldade reflete o longo período de colonialismo ao qual essa região esteve subjugada, não tendo ainda adquirido condições para sua autodeterminação.

A despeito, no entanto, desse quadro de problemas, a tomada de consciência, a mobilização do Governo e das instituições e os primeiros encaminhamentos que vêm sendo tomados nesses últimos anos, acenam para um recomeço em novas bases e perspectivas, que, coadjuvados por parcerias e cooperação continuadas, possibilitam vislumbrar, no longo prazo, resultados mais efetivos. 


\section{Referências}

BROWNE, S. Developing capacity through technical cooperation. New York: Earthscan Publications Ltd, UNDP, 2002.

CANTO, I.; HANNAH, J. Colaboração (neocolonial) avançada: um novo modelo entre o centro e a periferia. Revista Brasileira de Pós-Graduação. Brasília, DF, CAPES, v. 3, n. 6, p. 214-233, 2006.

CUNHA, J. S. C. A questão de Timor-Leste: origens e evolução. Brasília, DF: Instituto Rio Branco, 2001.

HULL, G.; CORTE-REAL, B. A. Identidade, língua e política educacional. Lisboa:

Instituto Camões, 2002.

JAPAN INTERNATIONAL COOPERATION AGENCY. Report on terciary education in Timor-Leste. Dili: MECYS, 2003.

NEAVE, G. Institutional management of Higher Education: trends, needs, and strategies for international cooperation. Paris: UNESCO, 1992. Documento interno.

SANTOS, Boaventura de Sousa (Org.). Conhecimento prudente para uma vida decente. São Paulo: Cortez, 2004.

UNITED NATIONS. Welcome to Timor-Leste: a guide compiled. Dili: UNMISET, 2003.

Recebido em: 09/07/2007

Aceito para publicação em: 30/07/2007 